\title{
BILATERAL TESTS FOR THE ASSESSMENT OF MANIPULATIVE SKILLS IN CHILDREN: DEVELOPMENT, RELIABILITY, AND VALIDITY
}

original paper

( ) University School of Physical Education in Wroclaw

DOI: https://doi.org/10.5114/hm.2019.83991

\author{
FRANJO LOVRIC ${ }^{1}$, IGOR JELASKA ${ }^{2}$, CAIN C.T. CLARK ${ }^{3}$, EMMA L.J. EYRE ${ }^{3}$, \\ DURDICA MILETIC ${ }^{2}$, PETRA MANDIC ${ }^{2}$ \\ ${ }^{1}$ Faculty of Science and Education, University of Mostar, Mostar, Bosnia and Herzegovina \\ ${ }^{2}$ Faculty of Kinesiology, University of Split, Split, Croatia \\ ${ }^{3}$ Centre for Sport, Exercise and Life Sciences, Coventry University, Coventry, United Kingdom
}

\section{ABSTRACT}

Purpose. The aim of the study was to develop bilateral tests for simultaneous quantitative and qualitative assessment of manipulative skills among 7-year-old children, and to examine the reliability and validity of the tests.

Methods. A sample of 78 (35 girls) children (aged $7.34 \pm 0.53$ years) were tested with 3 novel bilateral tests: Standing ball throwing, Bouncing the ball standing, and Dribbling the ball with the foot. Subsequently, the reliability and validity of the constructed tests were investigated.

Results. Very high between-participant reliability was demonstrated through high and stable Cronbach's alpha coefficient (0.94-0.98 for all tests), while relatively small coefficients of variation (0.03-0.12 for all tests) were observed. High values of correlation between expert judges' ratings, as well as intra-class correlation, for both left and right sides indicated excellent between-rater reliability (0.84-0.99 and 0.88-0.93 across all tests, respectively).

Conclusions. The tests are reliable and valid in 7-year-old children and may be used to promote the adoption of appropriate sport and physical activities. Future research should explore the influence of further fine and gross motor skills on motor development.

Key words: psychometric characteristics, measurement, fundamental movement skills, motor asymmetry, motor competence

\section{Introduction}

The mastery of fundamental movement skills (FMS), the basic building blocks of movement, is a prerequisite for children's physical, cognitive, and social development, and is suggested to provide the foundation for an active lifestyle [1,2], potentially to combat the global obesity epidemic [3, 4]. Although naturally developed through growth, children's free play is insufficient stimuli alone for optimal development of FMS [5], leading to a need for additional education and teaching in the field [6]. Furthermore, organised physical activity is shown to be strongly associated with FMS [7]. Current empirical data support the dogma that teaching programmes of physical education classes, globally, should be partially based on learning and mastering FMS $[8,9]$.

FMS are movement patterns that can be defined as locomotor or manipulative skills. While locomotor skills necessitate moving the body from one position to another (e.g., running, leaping, jumping, and galloping), manipulative skills refer either to receiving or to propulsion of an object with the hand or foot (i.e., throwing, kicking, striking, and catching) $[10,11]$.

In addition to locomotor and object control, competence in stability is also alluded to (i.e., balancing and twisting) $[12,13]$. It is evident that in all facets of FMS, manipulative skills are recognized as an indispensable part of the basic motor knowledge. Extending beyond FMS, a large number of sporting activities will

Correspondence address: Cain C.T. Clark, Centre for Sport, Exercise and Life Sciences, Coventry University, Alison Gingell building, Priory Street, CV1 5FB, United Kingdom, e-mail: Cain.Clark@coventry.ac.uk

Received: November 28, 2018

Accepted for publication: January 16, 2019

Citation: Lovric F, Jelaska I, Clark C.C.T. , Eyre E.L.J., Miletic D, Mandic P. Bilateral tests for the assessment of manipulative skills in children: development, reliability, and validity. Hum Mov. 2019;20(3):1-9; doi: https://doi.org/10.5114/hm.2019.83991. 
primarily depend on the quality of learned and developed basic building blocks, leading towards sportsspecific knowledge and competence. Despite mounting evidence for the benefit of qualifying FMS, there remains an over-predominance in focusing on the quantity of activity rather than the quality $[14,15]$. Only in contemporary works has there been a trend towards a joint consideration of quantification and qualification $[14,15]$, which is especially recommended for the assessment of motor tasks in younger age groups [16].

There are three accepted phases of motor knowledge development: the (1) initial, (2) basic, and (3) mature one [17]. During the development phase of FMS, the integration of all components of the learned movement structures in coordinated, resulting in accurate and effective performance [18]. Individuals who have not reached the mature phase in the development of biotic motor knowledge have a limited opportunity to progress in the acquisition of specific motor skills $[1,18]$. In accordance with the progressive and developmental nature of FMS and specific motor skills, the necessity of reliable and valid FMS assessment is axiomatic [19]. Notwithstanding this need, there is a distinct paucity of bilateral-specific FMS tests, and given the ipsilateral and contralateral nature of many sports, the development of valid bilateral assessments is warranted. Therefore, the aim of this study is twofold: first to construct, and subsequently to examine novel bilateral assessments of manipulative skills.

\section{Material and methods}

\section{Participants}

The sample included 78 children ( 35 girls, 43 boys) with an average age of $7.34 \pm 0.53$ years, from the same geographical location. The final sample only involved participants who were right-handed (4 lefthanded subjects were excluded), asymptomatic of ill health, without visible motor disturbances or injuries (3 subjects were excluded), and not engaged in additional sports activities outside of obligatory physical education classes (16 subjects were excluded).

\section{Variables}

Three bilateral tests for simultaneous qualitative and quantitative assessment of the degree of adoption of manipulative FMS were constructed: Standing ball throwing, Bouncing the ball standing, and Dribbling the ball with the foot. During motor performance, a model of error assessment was applied according to the seg- ment of knowledge [20], which is recommended for the evaluation of motor skills, particularly among younger age groups. Consequently, each skill performance was precisely divided into four topological segments for which evaluation criteria were identified, detailed in Tables 1-3. For each test, the result of the participant was obtained by summing the segmental qualitative performance assessments (maximal score: 8) and quantitative results (maximal score: 4), so the total assessment scale equalled 12 points. The described procedure united qualitative and quantitative assessment, further facilitating inspection of each of them separately. An expert evaluation was carried out through analysis of digital records by three independent expert judges with more than 15 years of experience in physical education. The average values of all expert scores were used to define each participant's score. Description of each newly constructed test is reported below.

Test name: Standing ball throwing (with left hand, with right hand) (Figure 1).

Place of performance: School gym.

Equipment: Tennis ball, meter.

Starting position: Feet shoulder-width apart, arms down next to the body, tennis ball in one hand.

Performance: When signalled 'GO,' the participant steps forward with the leg opposite to the arm they use to swing with body rotation and throws the ball. The task is to throw the ball as far as possible. The task is then completed with the opposite side of the body. A familiarization period was permitted.

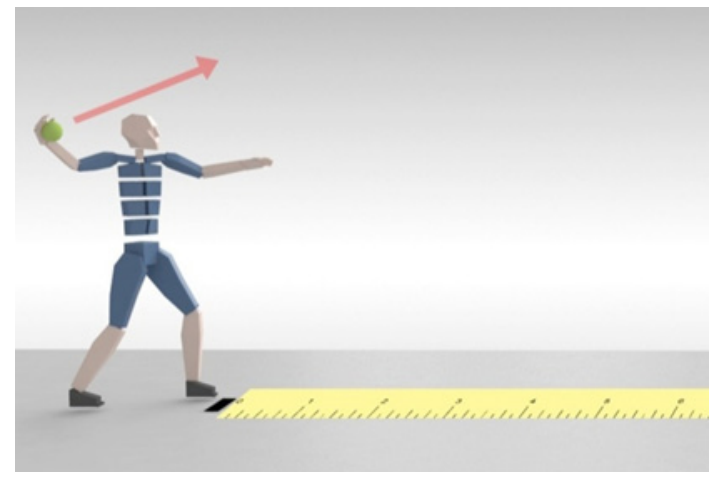

Figure 1. 3D view of Standing ball throwing performance

Test name: Bouncing the ball standing (with left hand, with right hand) (Figure 2).

Place of performance: School gym.

Equipment: Basket ball, $30 \times 30 \mathrm{~cm}$ area marked with tape, stopwatch.

Starting position: Participant stands on their right foot, with left leg bent at the knee to $90^{\circ}$, holding the ball in a front arm raise, arms bent at the elbows. 
Table 1. Standing ball throwing: judge's score card

Motor skill evaluated

Swinging the throwing arm while rotating the torso

Rotating the torso without arm swing

Throws the ball without swinging or rotation

With a slight bend in the throwing arm, moves to front arm raise

During the throw, separates the throwing arm from the body

During the throw, the throwing arm is lowered next to the body

During the throw, makes a step forward with the opposite leg

Makes a step forward with the opposite leg before the throw

Throws the ball without stepping forward

After the throw, raises the back leg, shifting weight to the front into the step forward

Shifts weight from the back leg without lifting it from the ground

Does not shift weight from the back to the front leg

Score

Quantitative assessment

The first $20 \%$ of the results

The second $20 \%$ of the results

The third $20 \%$ of the results

The fourth $20 \%$ of the results

The fifth $20 \%$ of the results

Table 2. Bouncing the ball standing: judge's score card

Motor skill evaluated

Score

Bounces the ball standing on one leg

Bounces the ball standing on one leg moving their foot

Bounces the ball with the opposite leg touching the ground

Bounces the ball in the area marked for leading

Bounces the ball partly disrespecting the marked area

Bounces the ball out of the marked area

Bounces the ball in the rhythm and height of the hips

Bounces the ball partly in the rhythm misbalancing the level of the ball leading

Fails to keep the rhythm and the level when bouncing the ball

Bounces the ball by pushing it in elbow joint and wrist

Bounces the ball pushing it in elbow joint without depreciation in the wrist

Fails to bounce the ball

Quantitative assessment

The first $20 \%$ of the results

The second $20 \%$ of the results

The third $20 \%$ of the results

The fourth $20 \%$ of the results

The fifth $20 \%$ of the results 


\section{HUMAN MOVEMENT}

F. Lovric et al., Bilateral assessment of children's movement

Performance: When signalled 'GO,' the participant puts the ball down with their right hand and starts bouncing. Standing on one leg, the subject performs 6 bounces of the ball into the bounded space. The task is repeated with the left hand. A familiarization period was permitted.

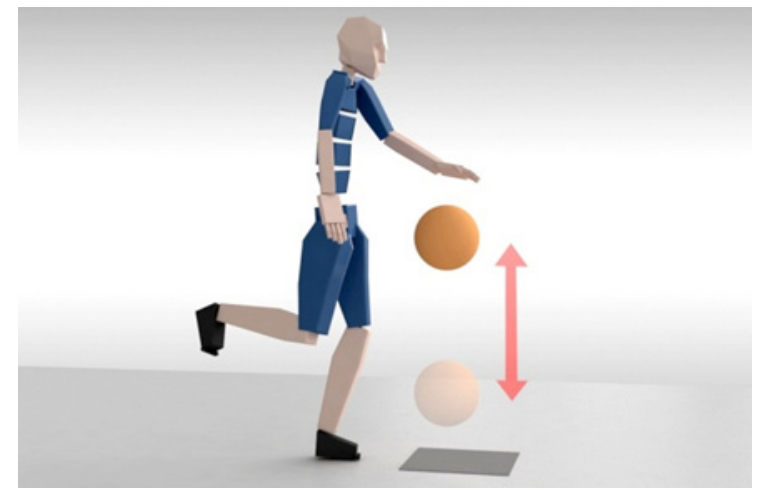

Figure 2. 3D view of Bouncing the ball standing performance
Test name: Dribbling the ball with the foot (with left leg, with right leg) (Figure 3).

Place of performance: School gym.

Equipment: Soccer ball, cones, tape.

Starting position: Participant stands in parallel position, arms next to the body, feet shoulder-width apart, a 10-metre track is demarcated with two cones, with a soccer ball at the starting cone.

Performance: When signalled 'GO,' the participant dribbles the soccer ball with the dorsal portion of their foot. The task is repeated with the left foot. A familiarization period was permitted.

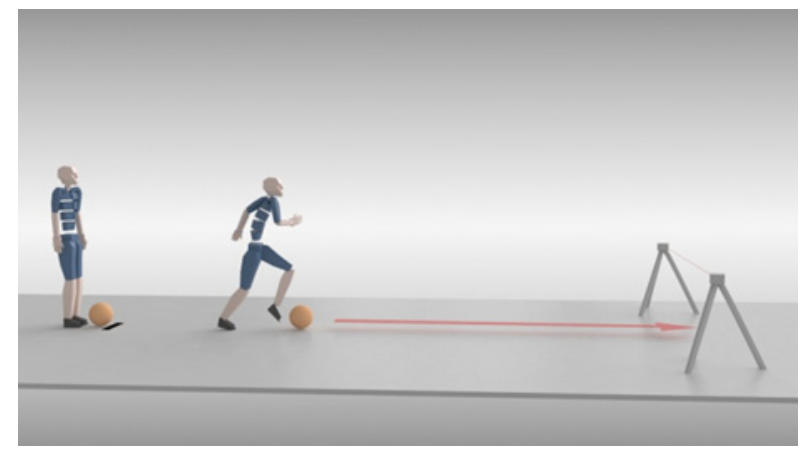

Figure 3. 3D view of Dribbling the ball with the foot performance

Table 3. Dribbling the ball with the foot: judge's score card

Motor skill evaluated

Performs the task in a straight line

Slightly deviates from the straight line

Straight line is visibly deteriorated

Whilst running, performs the task continuously controlling the ball

Partially disturbs the pace and continuity of performance

The pace and continuity of performance are visibly deteriorated

Dribbles the ball with upper foot

Partially dribbles the ball with upper foot

Does not lead the ball with upper foot

Whilst dribbling, alternately watches the ball and the direction, with the arms bent to the elbow Score

Whilst dribbling, alternately watches the ball and the direction, with an irregular position of the upper part of the body, arms to the body

Whilst dribbling, watches the ball constantly during leading

Quantitative assessment

The first $20 \%$ of the results

The second $20 \%$ of the results

The third $20 \%$ of the results

The fourth $20 \%$ of the results

The fifth $20 \%$ of the results 
Experimental procedure

All measurements were conducted in the same school gym, under the same conditions, and at the same time of day, to ameliorate the effect of diurnal variation. The parents/guardians were asked to confirm their child's health status prior to participation. Measurements were conducted on three successive days; during a single day, the subjects were measured three times in one test, firstly on their right side, and subsequently on their left side. The participants' trials were recorded in the mediolateral plane by a digital camera (HC-V770K Full HD Camcorder, 1080p, $20 \times$ digital zoom); after all recordings were collected, three expert judges (researcher, practitioner, and teacher) rated all performances in accordance with judge's score cards, as detailed in Tables 1-3.

\section{Data processing methods}

For both measured sides, all data were presented as mean \pm standard deviation, minimal and maximal result. The Kolmogorov-Smirnov test was used to confirm the normality of distribution prior to further inferential statistical tests. Because of construct validity assessment, exploratory factor analysis was applied, and factor structure matrix of the judges' scores was presented together with absolute and relative amount of variability of the judges' ratings related to single factors. Between- and within-participant reliability were assessed by using Cronbach's alpha $(\mathrm{C} \alpha)$ and coefficient of variation $(\mathrm{CV})$, respectively. Furthermore, the intra-class correlation coefficient (ICC) and average correlation among the judges' ratings (IIR) were applied for between-rater reliability. All calculations were performed with the Statistica 13.2 data analysis software system (Dell Inc., Tulsa, OK, USA). For all tests, the level of statistical significance was set as $\alpha=0.05$, with $95 \%$ confidence intervals presented when appropriate.

\section{Ethical approval}

The research related to human use has complied with all the relevant national regulations and institutional policies, has followed the tenets of the Declaration of Helsinki, and has been approved by the authors' institutional review board or an equivalent committee.

\section{Informed consent}

Informed consent has been obtained from the parents/guardians of all individuals included in this study.

\section{Results}

Very high between-participant reliability was demonstrated through high and stable C $\alpha$ coefficient (0.940.98 for all tests), while relatively small observed CVs (0.03-0.12 for all test) indicate appropriate withinparticipant reliability for all tests (Tables 4-6). High values of IIR, as well as ICC, for both left and right sides point at excellent between-rater reliability (IIR: 0.840.99, ICC: 0.88-0.93 across all tests) (Tables 4-6).

\section{Discussion}

A general observation is that boys tend to be more physically active than their female counterparts [21, $22]$, and generally display better object control skills than girls; however, evidence on sex differences in locomotor skills is much more equivocal [15, 23, 24], exemplifying the need for a specific locomotor testing battery. Contentiously, many studies show that girls outperform boys in locomotor skills [25-27], whilst a comparable number of studies assert that boys have equal [28, 29] or higher locomotor skill competence [30]; nevertheless, methodological issues or lack of specificity may be contributing to the discord across the literature. The present study proposes a new ontology, where reliable bilateral assessment of manipulative skills is focussed upon.

As detailed in Tables 4-6, very high between-participant reliability is identified through high and stable C $\alpha$ coefficient, while relatively small observed CVs indicate appropriate within-participant reliability for all tests. High values of IIR, as well as ICC, for both left and right sides point at excellent between-rater reliability (IIR: 0.84-0.99, ICC: 0.88-0.93 across all tests). This suggests that the judges had adequate preparation with clearly defined evaluation criteria for these tests [31]. The results of the present study, in terms of reliability, are similar to the widely known and eponymous Test of Gross Motor Development, $2^{\text {nd }}$ edition (TGMD-2) [20]. The TGMD-2 refers to 12 FMS, including locomotor and object control skills, and takes approximately $20 \mathrm{~min}$ to administer [20]. It is a qualitative measure in which each skill is scored against performance criteria prescribed in an accompanying manual (3-5 criteria per skill). Ratings in each item are, perhaps somewhat cumbersomely, summed to compute scores for locomotor and object control skills (each score ranging from 0 to 48). The psychometric properties of the TGMD-2 have been evaluated and the manual reports excellent test-retest reliability and inter-rater reliability $(r>0.85)$, as well as a good internal 


\section{HUMAN MOVEMENT}

F. Lovric et al., Bilateral assessment of children's movement

Table 4. Reliability and validity of the constructed Standing ball throwing test at three measurement points for both the left and right side

\begin{tabular}{|c|c|c|c|c|c|c|}
\hline & $\begin{array}{c}1^{\text {st }} \\
\text { measurement } \\
\text { right }\end{array}$ & $\begin{array}{l}2^{\text {nd }} \\
\text { measurement } \\
\text { right }\end{array}$ & $\begin{array}{c}3^{\text {rd }} \\
\text { measurement } \\
\text { right }\end{array}$ & $\begin{array}{c}1^{\text {st }} \\
\text { measurement } \\
\text { left }\end{array}$ & $\begin{array}{c}2^{\text {nd }} \\
\text { measurement } \\
\text { left }\end{array}$ & $\begin{array}{c}3^{\text {rd }} \\
\text { measurement } \\
\text { left }\end{array}$ \\
\hline $\mathrm{C} \alpha$ & & 0.98 & & & 0.96 & \\
\hline $\mathrm{CV}$ & & 0.03 & & & 0.09 & \\
\hline ICC & $0.91^{*}$ & $0.88^{*}$ & $0.91^{*}$ & $0.92 *$ & $0.90 *$ & $0.93 *$ \\
\hline $95 \%$ CI & $0.87-0.95$ & $0.86-0.91$ & $0.86-0.94$ & $0.89-0.96$ & $0.88-0.93$ & $0.89-0.96$ \\
\hline IIR & $0.98^{*}$ & $0.94^{*}$ & $0.97 *$ & $0.96^{*}$ & $0.97^{*}$ & $0.94^{*}$ \\
\hline $95 \%$ CI & $0.96-0.99$ & $0.92-0.97$ & $0.95-0.99$ & 0.93-0.99 & $0.95-0.99$ & $0.92-0.99$ \\
\hline S1 & -0.99 & -0.98 & -0.99 & -0.99 & -0.99 & -0.97 \\
\hline S2 & -0.99 & -0.97 & -0.99 & -0.99 & -0.99 & -0.98 \\
\hline S3 & -0.99 & -0.98 & -0.99 & -0.99 & -0.99 & -0.98 \\
\hline Var & 2.95 & 2.87 & 2.93 & 2.93 & 2.95 & 2.88 \\
\hline V\% & 98.49 & 95.65 & 97.66 & 97.55 & 98.24 & 95.89 \\
\hline KS-p & $<0.15$ & $>0.20$ & $<0.20$ & $>0.20$ & $<0.20$ & $>0.20$ \\
\hline M & 5.85 & 4.31 & 5.82 & 4.08 & 6.33 & 4.38 \\
\hline$\sigma$ & 3.42 & 2.40 & 3.39 & 2.54 & 3.50 & 2.64 \\
\hline Min & 0.00 & 0.00 & 0.00 & 0.00 & 1.00 & 0.00 \\
\hline Max & 12.00 & 9.00 & 12.00 & 12.00 & 12.00 & 11.67 \\
\hline
\end{tabular}

* significant at $p<0.05$

C $\alpha$ - Cronbach's alpha coefficient, CV - coefficient of variation, ICC - intra-class correlation coefficient, 95\% CI - 95\% confidence interval, IIR - average correlation between expert judges' ratings, S1, S2, S3 - factor structure matrix coefficients, Var - variance accounted for by the factor, V\% - proportion of variance accounted for by the factor, KS-p - significance of Kolmogorov-Smirnov test, $\mathrm{M}$ - mean, $\sigma$ - standard deviation, Min - minimum result, Max - maximum result

Table 5. Reliability and validity of the constructed Bouncing the ball standing test at three measurement points for both the left and right side

\begin{tabular}{|c|c|c|c|c|c|c|}
\hline & $\begin{array}{c}1^{\text {st }} \\
\text { measurement } \\
\text { right }\end{array}$ & $\begin{array}{l}2^{\text {nd }} \\
\text { measurement } \\
\text { right }\end{array}$ & $\begin{array}{c}3^{\text {rd }} \\
\text { measurement } \\
\text { right }\end{array}$ & $\begin{array}{c}1^{\text {st }} \\
\text { measurement } \\
\text { left }\end{array}$ & $\begin{array}{c}2^{\text {nd }} \\
\text { measurement } \\
\text { left }\end{array}$ & $\begin{array}{c}3^{\text {rd }} \\
\text { measurement } \\
\text { left }\end{array}$ \\
\hline $\mathrm{C} \alpha$ & 0.98 & & & 0.94 & & \\
\hline $\mathrm{CV}$ & 0.06 & & & 0.09 & & \\
\hline ICC & $0.93 *$ & $0.93 *$ & $0.93 *$ & $0.89 *$ & $0.91 *$ & $0.92 *$ \\
\hline $95 \%$ CI & $0.90-0.95$ & $0.91-0.96$ & $0.91-0.95$ & $0.83-0.95$ & $0.89-0.94$ & $0.90-0.96$ \\
\hline IIR & $0.95 *$ & $0.95 *$ & $0.96 *$ & $0.95 *$ & $0.94 *$ & $0.92 *$ \\
\hline $95 \% \mathrm{CI}$ & $0.91-0.99$ & $0.93-0.99$ & $0.94-0.98$ & $0.92-0.97$ & 0.92-0.97 & $0.89-0.97$ \\
\hline S1 & -0.98 & -0.98 & -0.98 & -0.99 & -0.99 & -0.99 \\
\hline S2 & -0.99 & -0.98 & -0.99 & -0.99 & -0.99 & -0.99 \\
\hline S3 & -0.98 & -0.99 & -0.99 & -0.99 & -0.99 & -0.99 \\
\hline Var & 2.90 & 2.99 & 2.92 & 2.94 & 2.96 & 2.66 \\
\hline V\% & 96.83 & 96.41 & 97.42 & 98.32 & 98.57 & 98.51 \\
\hline KS-p & $<0.15$ & $>0.20$ & $<0.05$ & $>0.20$ & $<0.10$ & $>0.20$ \\
\hline $\mathrm{M}$ & 5.17 & 4.44 & 5.18 & 5.34 & 6.48 & 6.61 \\
\hline$\sigma$ & 3.01 & 2.90 & 3.14 & 3.42 & 3.06 & 2.87 \\
\hline Min & 0.00 & 0.00 & 0.00 & 0.00 & 0.00 & 0.00 \\
\hline Max & 11.67 & 10.00 & 10.67 & 11.00 & 12.00 & 11.67 \\
\hline
\end{tabular}

* significant at $p<0.05$

C $\alpha$ - Cronbach's alpha coefficient, CV - coefficient of variation, ICC - intra-class correlation coefficient, 95\% CI - 95\% confidence interval, IIR - average correlation between expert judges' ratings, S1, S2, S3 - factor structure matrix coefficients, Var - variance accounted for by the factor, V\% - proportion of variance accounted for by the factor, KS-p - significance of Kolmogorov-Smirnov test, M - mean, $\sigma$ - standard deviation, Min - minimum result, Max - maximum result 
Table 6. Reliability and validity of the constructed Dribbling the ball with the foot test at three measurement points for both the left and right side

\begin{tabular}{lcccccc}
\cline { 2 - 6 } & $\begin{array}{c}1^{\text {st }} \\
\text { measurement } \\
\text { right }\end{array}$ & $\begin{array}{c}2^{\text {nd }} \\
\text { measurement } \\
\text { right }\end{array}$ & $\begin{array}{c}3^{\text {rd }} \\
\text { measurement } \\
\text { right }\end{array}$ & $\begin{array}{c}1^{\text {st }} \\
\text { measurement } \\
\text { left }\end{array}$ & $\begin{array}{c}2^{\text {nd }} \\
\text { measurement } \\
\text { left }\end{array}$ & $\begin{array}{c}3^{\text {rd }} \\
\text { measurement } \\
\text { left }\end{array}$ \\
\hline C $\alpha$ & 0.95 & & & 0.94 & & \\
CV & 0.08 & & & 0.12 & & $0.88^{*}$ \\
ICC & $0.90^{*}$ & $0.89^{*}$ & $0.90^{*}$ & $0.84^{*}$ & $0.92^{*}$ \\
95\% CI & $0.87-0.94$ & $0.85-0.93$ & $0.87-0.96$ & $0.79-0.93$ & $0.82-0.93$ & $0.85-0.95$ \\
IIR & $0.95^{*}$ & $0.95^{*}$ & $0.96^{*}$ & $0.92^{*}$ & $0.94^{*}$ & $0.95^{*}$ \\
95\% CI & $0.90-0.99$ & $0.91-0.97$ & $0.92-0.99$ & $0.87-0.97$ & $0.89-0.98$ & $0.90-0.99$ \\
S1 & -0.98 & -0.98 & -0.98 & -0.96 & -0.98 & -0.98 \\
S2 & -0.99 & -0.98 & -0.99 & -0.98 & -0.98 & -0.98 \\
S3 & -0.99 & -0.98 & -0.99 & -0.98 & -0.98 & -0.98 \\
Var & 2.90 & 2.89 & 2.91 & 2.83 & 2.89 & 2.90 \\
V\% & 96.79 & 96.48 & 96.99 & 94.43 & 96.20 & 96.61 \\
KS-p & $>0.20$ & $>0.20$ & $>0.20$ & $>0.20$ & $>0.20$ & $>0.20$ \\
M & 5.49 & 4.94 & 5.04 & 4.57 & 5.52 & 4.80 \\
$\sigma$ & 2.66 & 2.51 & 2.46 & 2.42 & 2.43 & 2.54 \\
Min & 0.00 & 0.00 & 0.00 & 0.00 & 1.33 & 0.00 \\
Max & 12.00 & 11.00 & 12.00 & 12.00 & 12.00 & 11.00 \\
\hline
\end{tabular}

* significant at $p<0.05$

$\mathrm{C} \alpha$ - Cronbach's alpha coefficient, CV - coefficient of variation, ICC - intra-class correlation coefficient, 95\% CI - 95\% confidence interval, IIR - average correlation between expert judges' ratings, S1, S2, S3 - factor structure matrix coefficients, Var - variance accounted for by the factor, V\% - proportion of variance accounted for by the factor, KS-p - significance of Kolmogorov-Smirnov test, $\mathrm{M}$ - mean, $\sigma$ - standard deviation, Min - minimum result, Max - maximum result

consistency ( $\mathrm{C} \alpha=0.85$ and $\mathrm{C} \alpha=0.88$ for locomotor and object control subtests, respectively). In fact, the present study has demonstrated preferential reliability and higher internal consistency (Tables 4-6). Where exploratory factor analysis resulted in an extraction of a single factor, a high percentage of explained variability was evident, with a score of more than $94 \%$ in all the tests; this indicates satisfactory construct validity of the tests for both sides of the body, at all three measuring points [32-34]. Notwithstanding, owing to the TGMD-2 popularity, construct, content, and concurrent validity have also been determined for children aged 3-10 years in the TGMD-2 [35, 36], in addition to the development of a third iteration of the test. Therefore, further work must seek to expand on the present study's promising results, and ascertain whether reliability and validity are retained across ages [37], whether actual results are concordant with the perceived skill level [38], and whether participation in sports concomitantly improves manipulative skills [39].

Observing all tests individually, reviewing the average values and other descriptive parameters of all six newly constructed tests, we can confirm very high sensitivity of these parameters; following analysis of mean values and comparison across all measurements, we found that the obtained results were stable. Abovementioned indicators clearly show the applicability of these tests, which, owing to well-established evaluation criteria and quantitative components, enable quality assessment and clear insight into the manipulative skills of 7-year-old children. Furthermore, a methodological base for further scientific research of factors that may affect the quality of motor skills performance is now established.

This study has multiple limitations to consider when interpreting our findings. Firstly, all raters assessed the performance of participants using video recordings, with only one plane of view available. Whilst this could conceivably impact the raters' perceptions, the same recordings were provided to each rater. Additionally, there were some constraints in the data collection process, such as space limitations, angle of the camera relative to the participant, and distance of the participant from the camera. However, all subjects were able to complete the assessment in accordance with the newly produced, standardized procedures, and raters had an acceptable view of all performances for scoring. A further, potential, ecological limitation is that because all scoring in this study was based on digitally recorded 
performances, reliability estimates should not necessarily be generalized to the professionals, educators, and other key stakeholders who would score the performances of children during live assessment. Therefore, it would be pragmatic that future research investigates the discrepancy, if any, between live and video-recorded assessment.

\section{Conclusions}

The importance of the present study is reflected in the fact that the newly constructed bilateral tests had satisfactory psychometric characteristics, which is conducive to further scientific research and practical use. Additionally, it should be emphasized that, although the newly constructed tests incorporate both qualitative and quantitative facets, they can be efficaciously operationalised to evaluate the respondents solely qualitatively (performance technique) or solely quantitatively (performance effectiveness). Furthermore, given that the newly constructed tests are bilateral, we can tentatively consider them as an instrument that can be utilised to detect manipulative skills as a whole rather than only unilateral elements. A prominent advantage of the tests is the fact that they are not financially burdensome and only require simple materials and conditions for their performance and measurement, and they take only a short amount of time to complete. Based on measures of reliability, the newly constructed bilateral tests can efficaciously be used for the assessment of manipulative skills in 7-year-old children, as a diagnostic tool, for transitional or developmental monitoring, or as an indicator of the efficacy of specific educational or training programmes that encourage children into sports activities, whilst helping to counter unilateral dominance. The authors assert that the evaluation and monitoring of manipulative skills within physical education classes, with additional teacher education, could be better and more easily realized, at no extra cost, with these newly constructed tools, facilitating the mastery or competency of sport specialised skills.

\section{Acknowledgements}

The authors wish to thank all the participants, guardians, and teachers who dedicated their time and attention to this work.

\section{Disclosure statement}

No author has any financial interest or received any financial benefit from this research.

\section{Conflict of interest}

The authors state no conflict of interest.

\section{References}

1. Gallahue DL, Donnelly FC. Developmental physical education for all children, $4^{\text {th }}$ ed. Champaign: Human Kinetics; 2003.

2. Lubans DR, Morgan PJ, Cliff DP, Barnett LM, Okely AD. Fundamental movement skills in children and adolescents: review of associated health benefits. Sports Med.2010;40(12):1019-1035; doi:10.2165/11536850000000000-00000.

3. Holfelder B, Schott N. Relationship of fundamental movement skills and physical activity in children and adolescents: a systematic review. Psychol Sport Exerc. 2014;15(4):382-391; doi: 10.1016/j.psychsport.2014. 03.005 .

4. Clark CCT. Is obesity actually non-communicable? Obes Med. 2017;8:27-28; doi: 10.1016/j.obmed.2017. 10.001.

5. Gagen LM, Getchell N. Using 'constraints' to design developmentally appropriate movement activities for early childhood education. Early Childhood Educ J. 2006;34(3):227-232; doi: 10.1007/s10643-006-0135-6.

6. Robinson LE, Goodway JD. Instructional climates in preschool children who are at-risk. Part I: object-control skill development. Res Q Exerc Sport. 2009;80(3):533542; doi: 10.1080/02701367.2009.10599591.

7. Jaakkola T, Kalaja S, Liukkonen J, Jutila A, Virtanen P, Watt A. Relations among physical activity patterns, lifestyle activities, and fundamental movement skills for Finnish students in grade 7. Percept Mot Skills. 2009;108(1):97-111; doi: 10.2466/PMS.108.1.97-111.

8. Aalizadeh B, Mohamadzadeh H, Hosseini FS. Fundamental movement skills among Iranian primary school children. J Family Reprod Health. 2014;8(4):155-159.

9. Zuvela F, Kezic A, Krstulovic S. Morphological and motor-functional factors influencing fundamental movement skills in eight-year-old children. Iran J Pediatr. 2016;26(6):e5709; doi: 10.5812/ijp.5709.

10. Gallahue DL, Ozmun JC, Goodway JD. Understanding motor development: infants, children, adolescents, adults, $7^{\text {th }}$ ed. Boston: McGraw-Hill; 2011.

11. Kirk MA, Rhodes RE. Motor skill interventions to improve fundamental movement skills of preschoolers with developmental delay. Adapt Phys Activ Q. 2011;28(3): 210-232; doi: 10.1123/apaq.28.3.210.

12. Gallahue DL, Ozmun JC. Understanding motor development: infants, children, adolescents, adults, $6^{\text {th }}$ ed. Dubuque: McGraw-Hill; 2005.

13. Rudd JR, Barnett LM, Butson ML, Farrow D, Berry J, Polman RC. Fundamental movement skills are more than run, throw and catch: the role of stability skills. PLoS One. 2015;10(10):e0140224; doi: 10.1371/journal.pone.0140224.

14. Clark CCT, Barnes CM, Swindell NJ, Holton MD, Bingham DD, Collings PJ, et al. Profiling movement and 
gait quality characteristics in pre-school children. J Mot Behav. 2018;50(5):557-565; doi: 10.1080/00222895. 2017.1375454.

15. Clark CCT, Moran J, Drury B, Venetsanou F, Fernandes J. Actual vs. perceived motor competence in children (8-10 years): an issue of non-veridicality. J Funct Morphol Kinesiol. 2018;3(2):20; doi: 10.3390/jfmk3020020.

16. Clark CCT, Barnes CM, Stratton G, McNarry MA, Mackintosh KA, Summers HD. A review of emerging analytical techniques for objective physical activity measurementin humans. Sports Med. 2017;47(3):439447; doi: 10.1007/s40279-016-0585-y.

17. Lloyd RS, Oliver JL. The youth physical development model: a new approach to long-term athletic development. Strength Cond J. 2012;34(3):61-72; doi: 10.1519/ SSC.0b013e31825760ea.

18. Goodway JD, Branta CF. Influence of a motor skill intervention on fundamental motor skill development of disadvantaged preschool children. Res Q Exerc Sport. 2003;74(1):36-46; doi: 10.1080/02701367.2003.1060 9062.

19. Cools W, De Martelaer K, Samaey C, Andries C. Movement skill assessment of typically developing preschool children: a review of seven movement skill assessment tools. J Sports Sci Med. 2009;8(2):154-168.

20. Ulrich DA. Test of Gross Motor Development: examiner's manual, $2^{\text {nd }}$ ed. Austin: PRO-ED; 2000.

21. Gortmaker SL, Lee R, Cradock AL, Sobol AM, Duncan DT, Wang YC. Disparities in youth physical activity in the United States: 2003-2006. Med Sci Sports Exerc. 2012;44(5):888-893; doi: 10.1249/MSS.0b013e3182 $3 f b 254$.

22. Schmutz EA, Leeger-Aschmann CS, Radtke T, Muff S, Kakebeeke TH, Zysset AE, et al. Correlates of preschool children's objectively measured physical activity and sedentary behavior: a cross-sectional analysis of the SPLASHY study. Int J Behav Nutr Phys Act. 2017;14(1): 1; doi: 10.1186/s12966-016-0456-9.

23. Barnett LM, Stodden DF, Cohen KE, Smith JJ, Lubans DR, Lenoir M, et al. Fundamental movement skills: an important focus. J Teach Phys Educ. 2016;35(3):219_ 225; doi: 10.1123/jtpe.2014-0209.

24. Barnett LM, Lai SK, Veldman SLC, Hardy LL, Cliff DP, Morgan PJ, et al. Correlates of gross motor competence in children and adolescents: a systematic review and meta-analysis. Sports Med. 2016;46(11):1663-1688; doi: 10.1007/s40279-016-0495-z.

25. Barnett LM, Morgan PJ, van Beurden E, Beard JR. Perceived sports competence mediates the relationship between childhood motor skill proficiency and adolescent physical activity and fitness: a longitudinal assessment. Int J Behav Nutr Phys Act. 2008;5:40; doi: 10.1186/1479-5868-5-40.

26. Liong GH, Ridgers ND, Barnett LM. Associations between skill perceptions and young children's actual fundamental movement skills. Percept Mot Skills. 2015; 120(2):591-603; doi: 10.2466/10.25.PMS.120v18x2.
27. Hardy LL, King L, Farrell L, Macniven R, Howlett S. Fundamental movement skills among Australian preschool children. J Sci Med Sport. 2010;13(5):503508; doi: 10.1016/j.jsams.2009.05.010.

28. Bardid F, Huyben F, Lenoir M, Seghers J, Martelaer K, Goodway JD, et al. Assessing fundamental motor skills in Belgian children aged 3-8 years highlights differences in US reference sample. Acta Paediatr. 2016;105(6):e281-e290; doi: 10.1111/apa.13380.

29. Slykerman S, Ridgers ND, Stevenson C, Barnett LM. How important is young children's actual and perceived movement skill competence to their physical activity? J Sci Med Sport. 2016;19(6):488-492; doi: 10.1016/j.jsams.2015.07.002.

30. Robinson LE. The relationship between perceived physical competence and fundamental motor skills in preschool children. Child Care Health Dev. 2011;37(4): 589-596; doi: 10.1111/j.1365-2214.2010.01187.x.

31. Smits-Engelsman BC, Fiers MJ, Henderson SE, Henderson L. Interrater reliability of the Movement Assessment Battery for Children. Phys Ther. 2008;88(2):286294; doi: 10.2522/ptj.20070068.

32. Chien CW, Brown T, McDonald R. Examining content validity and reliability of the Assessment of Children's Hand Skills (ACHS): a preliminary study. Am J Occup Ther.2010;64(5):756-767; doi:10.5014/ajot.2010.08158.

33. Lannin N. Reliability, validity and factor structure of the upper limb subscale of the Motor Assessment Scale (UL-MAS) in adults following stroke. Disabil Rehabil. 2004;26(2):109-116; doi: 10.1080/096382803200015 7970.

34. Valentini NC, Ramalho MH, Oliveira MA. Movement assessment battery for children-2: translation, reliability, and validity for Brazilian children. Res Dev Disabil. 2014;35(3):733-740; doi: 10.1016/j.ridd.2013.10.028.

35. Kim CI, Han DW, Park IH. Reliability and validity of the test of gross motor development-II in Korean preschool children: applying AHP. Res Dev Disabil. 2014; 35(4):800-807; doi: 10.1016/j.ridd.2014.01.019.

36. Valentini N. Validity and reliability of the TGMD-2 for Brazilian children. J Motor Behav. 2012;44(4):275280; doi: 10.1080/00222895.2012.700967.

37. Sokołowski B, Chrzanowska M. Development of selected motor skills in boys and girls in relation to their rate of maturation - a longitudinal study. Hum Mov. 2012; 13(2):132-138; doi: 10.2478/v10038-012-0014-5.

38. Afthentopoulou A, Venetsanou F, Zounhia A, Petrogiannis K. Physical activity, motor competence, and perceived physical competence: what is their relationship in children aged 6-9 years? Hum Mov. 2018;19(1):5156; doi: 10.5114/hm.2018.73612.

39. Chagas DV, Ozmun J, Batista LA. The relationships between gross motor coordination and sport-specific skills in adolescent non-athletes. Hum Mov. 2017;18(4): 17-22; doi: 10.1515/humo-2017-0037. 